\title{
Trends in Hyperglycemic Crisis Hospitalizations and in- and out-of-Hospital Mortality in the Last Decade Based on Korean National Health Insurance Claims Data (Endocrinol Metab 2019;34:275-81, Ji Hong You et al.)
}

\section{Ji Hong You, Sun Ok Song}

Division of Endocrinology and Metabolism, Department of Internal Medicine, National Health Insurance Service Ilsan Hospital, Goyang, Korea

We would like to thank Dr. Son for his careful and thorough reading of our article [1] and for providing thoughtful comments and constructive suggestions. As Dr. Son indicated, our findings are compatible with those of other studies. As mentioned in our article, the global epidemiologic data on hyperglycemic crisis are insufficient compared with the data available on diabetic ketoacidosis (DKA). Epidemiologic data are influenced by various factors, including but not limited to race, region, and socioeconomic status. Therefore, we hope that further epidemiologic studies of hyperglycemic crisis will be conducted in many countries.

Dr. Son also suggested that we conduct a further analysis of socioeconomic characteristics and regional differences in our data to find potential factors that influenced trends in hyperglycemic crisis. We agree that in order to prevent hyperglycemic crisis, it is important to find the reasons for which it occurs. Other studies have presented analyses of socioeconomic and regional differences in hyperglycemic crisis [2-4]. Although we did not include a description of regional differences in our article, some relevant data are available from a Korean report [5]. In brief, throughout Korea, the highest number of claims cases was in the age range of 70 to 79 years. The number of claims

Received: 28 November 2019, Accepted: 6 December 2019

Corresponding author: Sun Ok Song

Division of Endocrinology and Metabolism, Department of Internal Medicine, National Health Insurance Service Ilsan Hospital, 100 Ilsan-ro, Ilsandong-gu, Goyang 10444, Korea

Tel: +82-31-900-3470, Fax: +82-31-900-0519, E-mail: songso@nhimc.or.kr cases in Gyeonggi Province increased by $272.46 \%$ from 2004 to 2013 , while the number of those in Seoul increased by $215 \%$ during this 10 -year period. Additionally, the number of patients with diabetes in Korea has increased in recent years [6], with the sharpest increases in Seoul and Gyeonggi Province [7]. We infer that the number of claims cases for hyperglycemic crisis increased in these two regions because of a concomitant increase in the number of people with diabetes.

Dr. Son's last comment was that International Classification of Diseases (ICD) codes do not enable hyperosmolar hyperglycemic state (HHS) and mixed state of acidosis and hyperosmolarity to be distinguished from DKA. As Dr. Son pointed out, the ICD codes of HHS and mixed state were not clearly classified, at least to a certain degree. With our goal of evaluating overall trends in hyperglycemic crisis in Korea, we used a broad spectrum of ICD codes for hyperglycemic crisis. As briefly mentioned in our article, the broad spectrum of ICD codes does constitute a limitation that may have affected our results, including the observed trends. It is necessary to find a way to analyze the data in a more fine-grained way. It will also be necessary to consider various other factors, such as developments in treatment and the treatment and control rate of diabetes in order to

\section{Copyright $\odot 2019$ Korean Endocrine Society}

This is an Open Access article distributed under the terms of the Creative Commons Attribution Non-Commercial License (http://creativecommons.org/ licenses/by-nc/4.0/) which permits unrestricted non-commercial use, distribution, and reproduction in any medium, provided the original work is properly cited. 
predict future trends more precisely.

Dr. Son's valuable comments enable a more thorough understanding of our article. We deeply appreciate Dr. Son's comments, which have enriched our study.

\section{CONFLICTS OF INTEREST}

No potential conflict of interest relevant to this article was reported.

\section{ORCID}

Ji Hong You https://orcid.org/0000-0003-1544-7094

Sun Ok Song https://orcid.org/0000-0003-4829-3407

\section{REFERENCES}

1. You JH, Song SO, Park SH, Park KH, Nam JY, Kim DW, et al. Trends in hyperglycemic crisis hospitalizations and inand out-of-hospital mortality in the last decade based on Korean National Health Insurance Claims Data. Endocrinol Metab (Seoul) 2019;34:275-81.

2. Dabelea D, Rewers A, Stafford JM, Standiford DA, Lawrence JM, Saydah S, et al. Trends in the prevalence of ketoacidosis at diabetes diagnosis: the SEARCH for diabetes in youth study. Pediatrics 2014;133:e938-45.
3. Cacic P, Kruljac I, Cacic M, Peric B, Filipovic-GrcicM, Mirosevic G, et al. Incidence of diabetic ketosis and ketoacidosis in Caucasian adults with type 2 diabetes mellitus: a population-based study. Endocr Abstr 2017;49:EP463.

4. Wang J, Geiss LS, Williams DE, Gregg EW. Trends in emergency department visit rates for hypoglycemia and hyperglycemic crisis among adults with diabetes, United States, 20062011. PLoS One 2015;10:e0134917.

5. Song SO, Song YD, Kim DW, Nam JY, Park KH, Lee YH, et al. The index of medical utilization in hyperglycemic crisis over the last 10 years using National Health Insurance Claims data [Internet]. Goyang: National Health Insurance Service Ilsan Hospital; 2014 [cited 2019 Dec 6]. Available from: https:// www.nhimc.or.kr/cntFileDownLoad.do?DownLoadDir=/ down_data/audit/\&FileName $=$ audit05_etc08.pdf.

6. Song SO, Lee YH, Kim DW, Song YD, Nam JY, Park KH, et al. Trends in diabetes incidence in the last decade based on Korean National Health Insurance claims data. Endocrinol Metab (Seoul) 2016;31:292-9.

7. Song SO, Kim DW. Prevalence of diabetes and Characteristics in Korea over the last 10 years using National Health Insurance Claims data [Internet]. Goyang: National Health Insurance Service Ilsan Hospital; 2014 [cited 2019 Dec 6]. Available from: https://www.nhimc.or.kr/cntFileDownLoad. do?DownLoadDir=/down_data/audit $/ \&$ FileName $=$ audit05 etc25.pdf. 